\title{
Can a modified esophageal stent be useful in the treatment of nonresponsive benign colonic anastomotic stenosis?
}

A 77-year-old woman with history of anterior rectal resection for neoplasia in 1998, followed by chemo- and radiotherapy, was referred to our unit because of an increase in subocclusive episodes (1-2 times a week) over the previous 5 months, due to a stenosis extending to $5 \mathrm{~cm}$ above the colorectal anastomosis. The patient had previously undergone several pneumatic dilation procedures for anastomotic stenosis, with substenosis of the colon above, following radiotherapy.

A computed tomography scan showed a benign stenosis of the anastomosis extending to $5 \mathrm{~cm}$ of the colon above, with wall thickening from the development of fibrotic tissue after radiotherapy. We performed a colonoscopy to confirm the clinical scenario; the colorectal anastomosis was located $4 \mathrm{~cm}$ from the anal verge ( Fig. $\mathbf{1}$ ). We planned to place a modified, esophageal, large-diameter, fully covered, self-expandable metal stent (FCSEMS), with an anti-migration system and proximal head $(26 \mathrm{~mm}$ diameter, $100 \mathrm{~mm}$ length, $34 \mathrm{~mm}$ head; Taewoong Medical, Gyeonggi-do, South Korea).

Under deep sedation, the patient underwent lower endoscopy with a gastroscope. The proximal and the distal ends of the stricture were marked with a submucosal injection of radiopaque contrast medium. A guidewire (Jagwire; Boston Scientific, Marlborough, Massachusetts, USA) was advanced beyond the stenosis and the FCSEMS was placed over the wire ( $\triangleright$ Fig. 2 , \Video 1 ). The patient was discharged the day after the procedure.

The stent was removed 4 weeks later with a rat tooth forceps, and complete resolution of the stenosis could be observed ( Video 1 ). No adverse events were observed during the placement or removal of the stent. At 1 month followup, the patient was free of subocclusive symptoms.

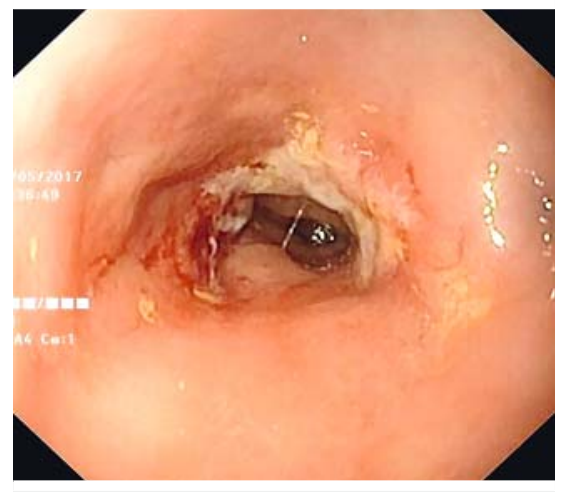

- Fig. 1 Substenotic colorectal anastomosis at $4 \mathrm{~cm}$ from the anal verge.

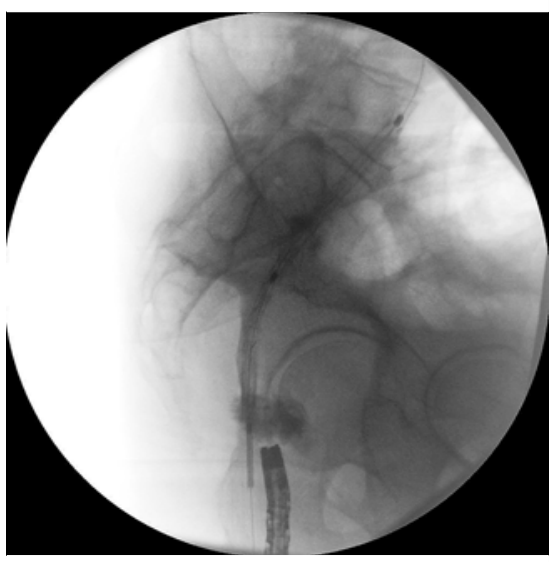

- Fig. 2 Radiological image of the fully covered, self-expandable, metal stent across the stricture, before its release.

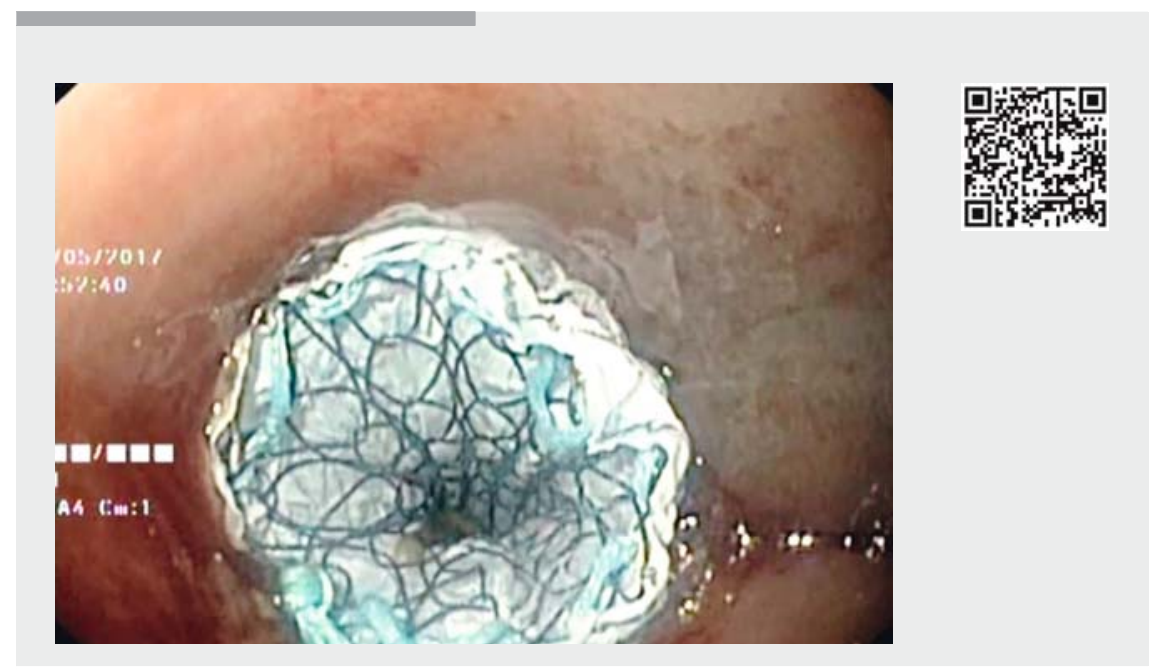

$\checkmark$ Video 1 Technical phases of the placement and removal of the fully covered self-expandable metal stent (FCSEMS). 1) Study of the colonic substenosis. 2) Marking the area by submucosal injection of contrast medium $1 \mathrm{~cm}$ above and below the stenosis. 3) Guidewire release. 4) FCSEMS placement.

In conclusion, the large-bore, modified, esophageal FCSEMS can be a valid alternative in the treatment of colorectal stenosis that is nonresponsive to other enCompeting interests doscopic treatments.

Endoscopy_UCTN_Code_TTT_1AQ_2AF 
The authors

Benedetto Mangiavillano ${ }^{1,2}$, Mario

Bianchetti ${ }^{1}$, Alessandro Repici ${ }^{2,3}$

1 Gastrointestinal Endoscopy Unit, Humanitas Mater Domini, Castellanza, Italy

2 Humanitas University, Milan, Italy

3 Digestive Endoscopy Unit, Istituto Clinico Humanitas Research Hospital, Rozzano, Italy
Corresponding author

Benedetto Mangiavillano, MD

Gastrointestinal Endoscopy Unit, Humanitas

- Mater Domini, Via Gerenzano n.2, 21053 -

Castellanza (VA), Italy

Fax: +39-0331-476372

b_mangiavillano@hotmail.com

\section{Bibliography}

DOI https://doi.org/10.1055/s-0043-119978

Published online: 17.10.2017

Endoscopy 2018; 50: E3-E4

(c) Georg Thieme Verlag KG

Stuttgart · New York

ISSN 0013-726X

\section{ENDOSCOPY E-VIDEOS}

https://eref.thieme.de/e-videos

回回 Endoscopy E-Videos is a free access online section, reporting 回㑇: on interesting cases and new techniques in gastroenterological endoscopy. All papers include a high quality video and all contributions are freely accessible online.

This section has its own submission website at

https://mc.manuscriptcentral.com/e-videos 